only in this eye, the distant vision being 6/6 unaided. The patient felt very comfortable for close work with this addition in the one eye.

I last saw the boy in March, 1936, and it was obvious that there was considerable lessening both of the dilatation and of the cycloplegia.

General. In this case the knee jerks were present and normal, and there were no signs of syphilis, or other history of diease, so far as I was able to ascertain. The Wassermann test was not thought necessary, and was not done.

Yours sincerely,

David T. Maclay, M.B.

6, Cecil Street,

Lytham-St,-Annes, April 6, 1936.

\title{
PSORIASIS AND EYE TROUBLE
}

To the Editors of The BRITISH JoURnal OF OpHThalmology.

SiRs,-Does Psoriasis appear on the Conjunctiva, and Margin of the Cornea?

The mucous membrane of the nose, larcrymal duct, and integuments of the face are often affected.

During the past 50 years I have seen several cases of Keratitis, a red ciliary zone, and inflamed conjunctiva, which I was inclined to consider as a spreading of this skin disease.

Should any of your readers have confirmatory evidence, it would be kind if they would communicate with me.

Yours faithfully,

W. Burrough Cosens.

28, LANSDOWNE ROAD.

TUNBRIDGE WELLS.

NOTES

The Royal London THE Annual Dinner of the Royal London Ophthalmic Hospital, Ophthalmic (Moorfields Eye) Hospital took Annual Dinner, 1936 place on Thursday, March 12, at the Langham Hotel. Sir John Herbert Parsons, C.B.E., D.Sc., F.R.C.S., F.R.S., presided, over a large attendance, including among others:- $\mathrm{Mr}$. Theodore Luling (chairman of the Hospital), Sir Keith Elphinstone, Lady Lister and Mr. K. G. R. Vaizey (members of the Lay Committee), Col. A. H. Proctor (Dean of the British Post-graduate School), Dr. A. M. H. Gray (Faculty of Medicine, London 